\title{
National beverages in a healthy diet system
}

\author{
Irina Bazhenova ${ }^{1, *}$, Elena Chernova $^{2}$, Tatiana Bazhenova ${ }^{3}$, and Valeria Bychenkova ${ }^{1}$ \\ ${ }^{1}$ Graduate School of Biotechnology and Food Production, Peter the Great St. Petersburg Polytechnic \\ University, St. Petersburg, Russia \\ ${ }^{2}$ Department of Hotel and Restaurant Business, Saint-Petersburg State University of Economics, St. \\ Petersburg, Russia \\ ${ }^{3}$ Institute of secondary vocational education. Peter the Great St. Petersburg Polytechnic University, St. \\ Petersburg, Russia
}

\begin{abstract}
Migration of people with different ethnic and cultural origins observed during past decade worldwide resulted in the introduction of national beverages into food markets. In this study, we have investigated and critically appraised properties and marketing potential of the KyrgyzKazakh beverage Maksim. This national non-alcoholic beverage is produced by mixed fermentation of milk in the presence of fried cereal such as barley, proso millet, oats, and corn. Pure cultures of lactic acid bacteria are used as a leaven for fermentation. Maksim is used as a thirst-quenching and tonic beverage. It could be also considered as functional food. While being dense, it serves as an excellent source of nutrients, fiber, vitamins, microelements, and other biologically active ingredients that offer health benefits that extend beyond basic nutrition. However, this beverage is not recommended for those affected by gluten sensitivity disorders. Here, we reviewed a number of different national beverages, assess physico-chemical properties of Maksym, and evaluate marketing strategies for the introduction of this beverage to Russian food markets. Although being unfamiliar to most of Russian consumers, this beverage is of interest due to its nutritional and thirst-quenching properties, and that a better advertisement strategies are needed to advance this healthy drink to food market. These strategies could include tasting, explanation of production process, historical and cultural origins of this beverage to general public.
\end{abstract}

\section{Introduction}

Mass migration of people all over the globe could characterize our modern world. Such migration in European Union alone has expanded from 63 to 82 million migrants per year [1]. Russian Federation faces somewhat similar trend: from 9.2 to 11.5 million people are migrating to the country annually. In fact, $97 \%$ of working migrants are coming from the from the states of the former USSR with $74 \%$ of them - from the Middle Asian countries including Kazakhstan, Uzbekistan, and Tajikistan [2]. There is a dynamic and intricate link between health and migration. The consumption of common national foods plays an important role in maintenance of health and national identity of the migrant, who bring their

\footnotetext{
${ }^{*}$ Corresponding author: irinabazhenova@mail.ru
} 
traditions and culture, including national foods, to the host country. Foods that were previously known only in specific areas of the world are becoming known and popular in other countries.

Drinks and beverages that provide nourishment and biologically active ingredients are the important components of national kitchens. For several centuries, nations develop a plethora of recipes of the national beverages characteristic for specific regions. Yet, two most common components of all of them are milk of different animals and cereal. Most commonly known are Ayran, Tan, Kumis, Katik, and Shubat. Ayran is produced from cow, goat or sheep milk by mixed fermentation using lactic acid bacteria (Lactobacillus delbrueckii subsp. Bulgaricus and Streptococcus thermophilus) and yeasts [3]. Tan, a tonic dairy beverage of the Caucuses, represent a mix of cow, goat, sheep, or buffalo milk with cold water and salt. On a Russian food market, Tan is represented by a large number of products with different flavorings including dill, mint, basil, and cucumber. Katik is common for Bulgaria and Middle Asia, and it has a more than 2 thousand year history. It is produced by lacto-acidic fermentation of cow, goat, sheep or buffalo milk using Lactobacillus delbrueckii Bulgaricus and homofermentative lactic acid Streptococcus. Similar production technology is used for making Matsoni, which is widely known in the Caucasus region. Kumis, a typical Middle Asia and Middle East beverage that is also known in some regions in Africa and Southern America is also produced by fermentation of a fresh horse or camel milk using specific lactic acid bacteria and yeasts. Due to its healing powers, the Kumis-based therapy was developed in the mid 19 century for the treatment and prophylactics of anorexia, tuberculosis, of gastric disorders $[4,5]$. Another interesting beverage known to Buryats, Mongols, Tuva and other nationals of the North-Eastern Asia is Kurunga. It is produced by double, lactic acid and alcohol fermentation [6]. Narine - is a dairy product produced by acidophilic fermentation with Lactobacterium acidophilum.

Danish Ymer is another example of the soured milk product that is made by fermentation of the the whole milk with Lactococcus lactis using mesophylic leaven, which provides bubble and aroma to the beverage that containes $3.5 \%$ of fat and $5.6 \%$ of protein [7].

In Mongolia, Buryatia, Kalmikia, Tyva and in Altai region is know for Tarak. This beverage is produced from cow, sheep or goat milk using leaven from wheat, bark of young willow (Salix), rye bread, or old Tarak [8]. Tarak is distinct from many other milk-based beverages by the use of Swiss bacillus, a variety of the lactic acid bacillus that grows only in highlands of Altai, Baikal, and Western Caspian regions [9].

Shubat, one of the common Kazakhstan camel milk-based beverages, is known for its medicinal applications: it is usually recommended for people suffering from stomach ulcers, asthma, tuberculosis, disorders of pancreas and nervous system [10].

Iceland is known for the diary product Skyr, which resembles sour cream or curd cheese with slightly sour flavor. Skyr is referenced in the ancient Icelandic chronicals and it was made from the fresh whole milk. Nowadays, it is mostly produced from pasteurized fat-free milk by fermentation with Streptococcus salivarius subsp. thermophilus u Lactobacillus delbrueckii subsp. bulgaricus [11].

Another beverage that resembles the sour cream with high fat content up to $30 \%$ is French Cream-Fresh. It is prepared from half and half and cow milk leaven with addition of garlic, greens, and gelatin for the preparation of soups and souses without thermal treatment [12].

All national milk-based beverages are a great source of easily digestible proteins, carbohydrates, emulsified fats, and contain large quantities of vitamins C, A, D, PP, E, B as well as microelements including magnesium, phosphorus, potassium, and lactic acid. Some of these beverages also contain biotin and ethyl alcohol. All these beverages could improve functioning of gastro-intestinal tract, intestinal microflora, and immune system. Theses beverages could be used for the development of novel technologies for the production of functional foods that support active lifestyle, well-being and longevity. 
Modern food science develops toward foods with targeted action to support specific functions of the body. However, systematic scientific and technological investigations of multiple cereal-based national beverages are rarely conducted and a plethora of national recipes that could provide benefits to support healthy microbiota of intestinal tract and modern active lifestyle remained overlooked [13, 14, 15]. One of the most is Kvas. The first reference to this beverage could be found in chronicles dated 1056, although it is believed that this beverage appeared about $200-250$ years earlier. This non-alcoholic beverage possesses fragrant aroma of the baked rye bread with slightly acidic sweetened taste. Traditionally, it is believed that this beverage was invented in Russia, but Kvas is also known and produced in Byelorussia, Baltic states, Poland, and other countries [16, 17, 18]. Kvas is a product of mixed alcoholic and lactic acid fermentation that also provide refreshing and thirst-quenching properties to this beverage and lactic acid bacteria used in Kvas production also support healthy microbiota of the intestine. At the same time, nutritional valure of this beverage is ranging between 200 and $300 \mathrm{Cal}$ per liter [16]. Somewhat similar product known in Poland since XVI century is called Podpiwek. It is made from the products of the first round of beer fermentation [19].

Not all cereal-based national beverages are produce by specific type of fermentation. Production of well-known Swiss beverage Ovaltin (original name Ovomaltine) traditionally uses malt (germinated and hot-dried cereal grain) and egg with undefined enzymatic activities activated during malting. At present, Ovaltin production technology is substantially modified and current recipes include a variety of tastes including a popular instant chocolate variety that could be used as a hot and cold milk beverage [20]. Germany also produce similar beverage from fermented cereal (rye, wheat, oats) of a yellow color with distict task of bread. This beverage somewhat resembles acidic Kvas with low caloric value $(4.3 \mathrm{cal} / 100 \mathrm{ml})$ and contains about $1 \%$ and $0.05 \%$ of lactic and acetic acids, respectively [17]. In Americas, the most frequent ingredient of different beverages in corn. Thus, in Mexico and Central America, a popular beverage, Atole, is produced from corn flour and sugar cane with addition of milk and flavorings such as cinnamon and mint, whereas in Pery its variety is produced from purple corn and is known as Chicha morada [21, 22, 23]. In India and Asia, different national beverages are based on fermented rice [14].

Considering that there are only few manufacturers that produce national beverages for Russian food market, we have investigated phyciso-chemical properties of the Kirgiz-Kazakh beverage Maksim. The traditional recipes for this beverage originate centuries ago, when it was produced in fermented and non-fermented varieties and was an important part of traditional foods. Due to its nutritional value, it was widely used by herders and workers as a substitute for a cooked meal [24]. In the past, as well as nowadays, Maksym is produced by mixed fermentation of milk using pure cultures of lactic acid bacteria and yeasts and fried cereals (barley, proso millet, oats, and corn). It has a distinct slightly acidic salty taste with a pleasant smell of fried serial and is a highly potent thirst and hunger quencher and tonic [25, 26]. Kirgiz people consider Maksym as an elixir of life and longevity. It is an excellent source of digestible carbohydrates, vitamins, and fiber (Table 1) [27]. This beverage contains $19.33 \pm 0.68 \%$ of sediment, $5.04 \pm 0.3 \%$ of dry components, $0.35 \pm 0.10 \%$ of ethyl alcohol, and had a titrated acidity of $4.48 \pm 0.23 \mathrm{~cm}^{3}$ [28]. Cereal-derived sediment contains large quantities of minerals including silicon that is essential for protein-protein interactions in the skin, nails, hair and is essential for water retention in these epithelial tissues. Some data suggest that it is also preventive of atherosclerosis and Alzheimer disease [29, 30]. 
Table 1. Chemical composition of beverage Maksym.

\begin{tabular}{|c|c|c|c|c|c|c|}
\hline \multirow[b]{2}{*}{$\begin{array}{l}\text { Protein, } \\
\quad \mathrm{g}\end{array}$} & \multirow[b]{2}{*}{$\begin{array}{c}\text { Carbohydrates, } \\
\text { g }\end{array}$} & \multicolumn{4}{|c|}{ Vitamins Energy value, kcal } & \multirow{2}{*}{$\begin{array}{c}\text { Vitamins } \\
\text { Energy } \\
\text { value, } \text { kcal }\end{array}$} \\
\hline & & $\begin{array}{c}\text { B1, mg\% } \\
\text { B2, mg\% } \\
\text { PP, mg\% } \\
\text { C, g\% }\end{array}$ & $\begin{array}{c}\text { B1, mg\% } \\
\text { B2, mg\% } \\
\text { PP, mg\% } \\
\text { C, g\% }\end{array}$ & $\begin{array}{c}\text { B1, mg\% } \\
\text { B2, mg\% } \\
\text { PP, mg\% } \\
\text { C, g\% }\end{array}$ & $\begin{array}{c}\text { B1, mg\% } \\
\text { B2, mg\% } \\
\text { PP, mg\% } \\
\text { C, g\% }\end{array}$ & \\
\hline 0,9 & 4,4 & 0,08 & 0,1 & 0,4 & 0,59 & 27 \\
\hline
\end{tabular}

Maksym also known for the inhibition of severe intestinal infection with Salmonella, Staphylococcus aureus and other bacterial and parasites that cause dysentery. High content of Lactobacillus plantarum provides antagonistic effect to Helicobacter pylori, a known causative of stomach ulceration [26]. In the past, using traditional Maksym, we have developed a modified recipe of this beverage adjusted to Russian consumer [28].

However, considering a number of cereals used in all recipes, this beverage cannot be consumed by those suffering from gluten sensitivity disorders.

The goal of the current study was to conduct marketing analysis to define the potential of Maksym in Russian food market.

\section{Methods of research}

In the current study, general (collection, systematization, synthesis, and analysis) and marketing (survey and interview) evaluation methods were used. We have developed two questionnaires for survey with 10 questions and for the interview with 6 questions. Questions were aimed at evaluation of the responders' option about non-alcoholic traditional beverages, traditional cereal-based beverages, and specific questions about Maksym. Marketing evaluation was conducted in a"Pearl Plaza" shopping mall located at Petergoff Ave, 51A in St-Petersburg, Russia in June, 2020. A total of 280 responders were involved in the study: 200 people took part in the survey and 80 people were interviewed. Statistical analysis was done on digitized data using statistical algorithms of the Excel software. The data was considered statistically significant with $p$-value $\leq 0.05$.

\section{Research results}

Based on collected data, marketing analysis demonstrated that cold non-alcoholic beverages are commonly consumed by $91 \%$ of responders and that people of 18-23 and 35-50 years of age regularly consume such beverages. Interestingly, the first (younger) cohort of responders prefers carbonated beverages, whereas the second (older) cohort prefers ogshsu and mineral water. It was noted that majority of responders prefer domestic beverages produced in Russian Federation and in the neighboring Commonwealth of Independent States (CIS) over imported non-alcoholic beverages. Out of all responders, only $18 \%$ preferred imported beverages. In part, such preference could be explained by the currently on-going state politics of import substitution. This, in a long run, could have a very positive effect on the development of consumers' interest to national and ethnic foods and expansion of traditional recipe-based food markets. This trend is of particular importance to the cities with a large number of migrants and where development of technologies for production of national recipe-based foods may lead to a substantial interest from the consumers. Properly developed marketing strategies aimed at promoting such foods could secure the position of national foods and beverages in food markets of the Commonwealth. Furhter, our analysis demonstrated that only $6 \%$ of the responders knew about Maksym and that $62 \%$ of all responders expressed their interest in tasting this beverage. Thirty eight percent of responders were skeptical about an unusual product (Maksym) and its advertised potential benefits. Nevertheless, considering reference above trend, it is plausible that these responders could 
be persuaded in tasting Maksym to form experience-based opinion to appreciate its potential benefits.

Maksym is a healthy diet product and a functional food that offer health benefits beyond basic nutrition. Respectively, marketing strategies should be based on the engagement of the consumer. From the marketing point, a consumer does not buy the product but rather a possibility to satisfy specific needs. For the advancement of the national products at a stage of motivating the potential consumers it is important to consider that in the modern world marketing segmentation is not based on age, gender, or income, as it was in a prior century, but rather on a lifestyle and habits of the potential consumers. Respectively, Maksym could be advertised, first and foremost, to those who followed healthy lifestyle, appreciate good nutrition combined with healthy eating habits, and physical fitness. Targeting of this population could create a well-accepted trend and expand targeted audience. Nutrition value and multifactorial health benefits along with proper advertisement and pricing should be the key factors in the marketing of Maksym and similar national foods.

\section{Conclusions}

Maksym is an national Kazakh-Kirgiz beverage that is produced from the mixed fried cereal (barley, proso millet, oats, and corn) and fermented milk. It is an excellent thirst and hunger quencher and tonic. Physico-chemical composition of this beverage as well as organoleptic evaluation allowed us to suggest that introduction of Maksym as a non-alcoholic beverage to city dwellers could greatly benefit the overall health of the population. This beverage could be advertised to those who are not familiar with this product as a nourishing and functional food enrich with vitamins, microelements, and nutrients. Marketing strategy should be based on the popularization of a traditional, centuries-long experience, and on potential health benefits. It is expected that besides migrant from Kazakhstan and Kirgizstan, this beverage could be of a great interest to many Russian consumers. Considering a healthy lifestyle and fitness as an overall modern trend, it is expected that proper advertisement and pricing strategies, introduction of historical and traditional views, and Maksym tasting should create a popular demand on this and other national beverages. The advancement of the traditional functional foods, such as Maksym, to Russian food markets also require considerable interest from food production and food crevice (restaurants, cafes) businesses, to develop production and distribution chains aimed at traditional national products that could benefit the well-being of the population.

\section{References}

1. International Organization for Migration, Report on migration in the world (MOM) (2020)

2. Yu. F. Florinskaya, N. V. Mkrtchyan, Monitoring of the economic situation in Russia. Trends and challenges of socio-economic development, 30 (132) (2020)

3. G. Gudmundsson, K. Kristbergsson, Modernization of Traditional Food Processes and Products (2016)

4. G. Mogensen, Desalination, 35 (1980)

5. F. Altay, Yogurt in Health and Disease Prevention (2017)

6. O. V. CHugunova, M. P. Solov'eva, Management, 11-12(27-28) (2011)

7. T. Dhewa et al., Fermented Milk and Dairy Products (2015)

8. V. I. Rassadin, S. M. Trofimova, Tomsk J. LING\&ANTHRO, 4(26) (2019) 
9. Yu. A. Irgit, Materialy XII International Scientific Conference "Student Scientific Forum", (2020)

10. A. Amangel'dina, B. T. Abdizhapparova, N. S. Hanzharov, Bulletin of Science of Southern Kazakhstan, 3(3) (2018)

11. L. Meunier-Goddik, Handbook of Animal-Based Fermented Food and Beverage Technology (2012)

12. Y. Xiong, P. Zhang, R. D. Warner, S. Shen, Z. Fang, Critical reviews in food science and nutrition, Ahead-of-print, 1-25 (2020)

13. H. Gambuś, B. Mickowska, H. J. Barton, G. Augustyn, J. of Microbiology, Biotechnology and Food Sciences 4(3) (2015)

14. M. Rae, K. Ghosh, S. Singh, K. C. Mondal, J. of Ethnic Foods, 3(1) (2016)

15. J. Bazarnova, S. Eliseeva, N. Zhilinskaya, N. Barsukova, E. Aronova, A. Korzh, E3S Web of Conferences, 161 (2020)

16. M. N. Eliseev, A. E. Patalaha, S. V. Volkovich, Beer and drinks, 5 (2008)

17. K. V. Kobelev, Scientific substantiation and development of innovative technologies of grain-based beverages and their identification (2018)

18. A. M. Ivashkevich, Materials of the III International Scientific and Practical Conference of Students and Young Scientists (2019)

19. D. Vargas-Yana, B. Aguilar-Morón, N. Pezo-Torres, K. Shetty, L. G. Ranilla, J. of Ethnic Foods, 7 (2020)

20. H. V. Kuhnlein et al., Documenting traditional food systems of indigenous peoples: international case studies, (2006)

21. L. A. Oganesyanc, A. L. Panasyuk, M. V. Gernet, Soft drink technology (2018)

22. L. M. Valdez, Production and Management of Beverages, 1 (2019)

23. G. Fox, Starch in Food: Structure, Function and Applications (2018)

24. T. Borubaev, Kyrgyz cuisine, (1982)

25. S. T. Kyshtobaeva, T. T. Mamyrbaeva, A. B. Cherikchieva, Central Asian Medical Journal, 2-3 (2003)

26. L. G. Bazhenov, V. M. Bondarenko, E. A. Lykova, D. K. Ogaj, Journal of Microbiology, Epidemiology and Immunobiology, 3 (1997)

27. The company "Kyrgyz national soft drink" (zharma), https://www.open.kg.

28. I. Bazhenova, E. Chernova, T. Bazhenova, E3S Web of Conferences, 247 (2021)

29. KR. Martin, J Nutr Health Aging, 11(2) (2007)

30. S. Gilette Guyonnet, S. Andrieu, B.Vellas, J Nutr Health Aging, 11(2) (2007) 